\title{
Notas preliminares de uma crítica feminista aos programas de transferência direta de renda - o caso do Bolsa Família no Brasil
}

\section{Preliminary notes of a feminist criticism to the income transfer programs - the case of "Bolsa Família no Brasil"}

Artigo

Original

\section{Simone da Silva Ribeiro Gomes ${ }^{1}$}

Original

Paper

\section{Palavras-chave: \\ Programa Bolsa \\ Família}

Feminismo

Regulação

\section{Resumo}

Nos últimos anos, os programas de "luta contra a pobreza" e transferência direta de renda estão presentes na maioria dos países latino-americanos. A partir do primeiro ano de governo do presidente Lula (2003), o Brasil enfatiza essa forma de política social, ao unificar diferentes modelos de transferência do governo anterior (1995-2002) em um só programa: o Bolsa Família. O presente artigo busca expor a crítica da regulação da pobreza e o impacto das condicionalidades referentes a esta lógica de intervenção na reprodução social de um grupo específico. A relação entre o Estado e as mulheres - responsáveis únicas pelo sustento financeiro de suas casas e, majoritariamente, as maiores beneficiárias destes programas - é caracterizada por atravessamentos em termos de classe social, gênero e raça. Ao apresentar a perspectiva feminista, este artigo procura abrir uma série de questões ao analisar como as condicionalidades impostas pelo Programa Bolsa Família tendem a naturalizar o papel reprodutivo das mulheres na sociedade brasileira, limitando seu espaço de agenciamento e emancipação.

\section{Abstract}

In the last few years programs designated to "fight against poverty" and the income transfer are present in most of the Latin-American countries. After the first year of President Lula's government (2003), Brazil emphasizes this kind of social politics, by unifying different models of transfer, from the previous government (1995 - 2002), in the same program: "Bolsa Familia". This article aims to expose the poverty regulation criticism and the impact on conditionalities that refer to this logic of intervention in the social reproduction of a specific group. The relation between the State and women-sole responsible for the financial budget of their houses and the main benefitted people of the program - is characterized by a going through in terms of social class, gender and race. By presenting the feminist perspective this article tries to open a series of questions on how these conditionalities imposed by the "Bolsa Familia" Program tend to make natural the reproductive role of the women in the Brazilian society, limiting their space in the management and emancipation.
Key words:

"Bolsa Família”

Program

Feminism

Regulation
Recebido em 03/2011

Aprovado em 04/2011 


\section{Os programas de transferência direta de renda e o caso do Programa Bolsa Família - contexto e alguns dados}

Os programas de transferência direta de renda devem ser considerados frente a um contexto que busca responder aos Objetivos do Milênio ${ }^{2}$ e sua meta de reduzir pela metade a extrema pobreza até o ano de 2015. Os indicadores de progresso dessas iniciativas demonstram um entendimento individualizado da pobreza e que sua mensuração é baseada em características isoladas dos sujeitos, deixando de lado análises que considerem características como raça e gênero, entre outros índices. Apesar disso, a pobreza brasileira sabidamente possui características femininas e negras, demonstrando que as mulheres sofrem com subordinações de tipo econômico e identitárias.

Essas políticas foram amplamente adotadas nos últimos anos como o meio mais eficaz de luta contra a pobreza em diversos países em desenvolvimento. Entre suas características principais destaca-se i) uma transferência direta de dinheiro; ii) um público alvo definido e iii) um sistema de vigilância eficaz. Além disso, uma vez colocadas em prática, afetam pouco os orçamentos governamentais e são relativamente fáceis de administrar, quando considerada a extensão da sua aplicação nos municípios brasileiros e sua distribuição, através da utilização das redes bancárias.

O Brasil é um país de nível de renda intermediário, um PIB (em dólares) de cerca de 1 trilhão e meio e uma população total de 194 milhões de habitantes, em 2009³. A aplicação do Programa Bolsa Família (PBF) 4 no país, com o status de política social, data de 2003 e teve o modelo inicialmente desenvolvido no México em curso desde 1997, atualmente, denominado «Oportunidades» como inspiração ${ }^{5}$. Além do México e Brasil, cerca de 12 países da América Latina possuem programas similares, imple- mentados a partir dos anos 90 (LINDERT; LINDER; HOBBS; BRIÈRE, 2007).

Assim como o PBF, os demais programas de transferência de renda são, desde 2003, valorizados e tidos como exemplos por instituições internacionais (agências de cooperação multilaterais, em especial o Banco Mundial e o Banco Interamericano de Desenvolvimento). Entretanto, a gênese de tais políticas não está em movimentos da sociedade civil, mas sim, na administração pública, sendo ela a responsável por designar as zonas geográficas que são objetos da intervenção e definição da quantia dos benefícios e suas condicionalidades (Lautier, 2006).

Recuperando a lógica de outros programas, o Programa Bolsa Família tem como princípio de funcionamento uma quantia repassada pelo governo brasileiro mensalmente para as famílias consideradas "pobres" e "muito pobres", com condicionalidades nas áreas de educação e saúde . No que tange à educação, a condicionalidade demanda a presença obrigatória de crianças entre 6 a 15 anos, em 85\%; e adolescentes entre 16 e 17 anos, em 75\% das aulas. Os cuidados referentes à saúde ${ }^{6}$ são relativos ao seguimento do calendário de vacinação para as crianças menores de 7 anos, e os cuidados pré-natais para as mulheres grávidas entre 14 a 44 anos.

O Ministério do Desenvolvimento Social e Combate à Fome (MDS) trabalha com quatro tipos de benefícios: i) o benefício básico pago para famílias que não possuam crianças; ii) o benefício variável para as famílias com crianças; iii) o benefício variável vinculado ao adolescente; e iiii) o benefício variável de caráter extraordinário, que é o único que tem seu valor calculado caso a caso.

O histórico das políticas sociais no Brasil, entre os quais o Bolsa Família se insere, conta com o BPC (Benefício de Prestação Continuada $)^{7}$ e as Aposentadorias Rurais Não Contribuitivas $^{8}$. Além disso, o PBF é precedi-

${ }^{2} \mathrm{~A}$ declaração dos Objetivos do Milênio pelo desenvolvimento (OMD), de 2000,assinada por 189 países, possui 8 objetivos, sendo o primeiro reduzir a pobreza extrema e a fome.

${ }^{3}$ Segundo o Banco Mundial, fonte : http://donnees.banquemondiale.org/pays/bresil

${ }^{4} \mathrm{~A}$ política em curso foi regulamentada por meio da Portaria Interministerial do Ministério da Saúde e Ministério do Desenvolvimento Social e Combate à Fome ${ }^{\circ}$ 2509, de 18/11/04. (Freitas, 2008)

sÉ interessante notar que em 1996 o governo Mexicano enviou uma delegação para o Brasil para investigar o "Bolsa Escola", precursos do Bolsa família, para o seu primeiro programa de transferência de renda, "Progresa", posteriormente denominado "Oportunidades", em 2002.

${ }^{6}$ Segundo o Ministério do Desenvolvimento Social, em : http://www.mds.gov.br/bolsafamilia/beneficios.

${ }^{7}$ Instituido em 1993, é um benefício pago pelo Governo Federal, assegurado por lei, à idosos e pessoas com deficiência. Fonte: http://www.mpas.gov.br/ conteudoDinamico.php?id=23

${ }^{8}$ Instituídas em 1991, que ofereciam uma renda estipulada e equivalente ao salário mínimo da época. 
do e incorporou em seu funcionamento o primeiro programa de transferência de renda, o Programa Bolsa Escola ${ }^{9}$; Bolsa Alimentação ${ }^{10}$ ; Auxilio Gás ${ }^{11}$ e o Programa de Erradicação do Trabalho Infantil (PETI) ${ }^{12}$.

Considerando tal histórico, a boa avaliação ${ }^{13}$ do Programa é atribuída, em parte, à unificação das políticas sociais do governo Lula, que envolveu desafios de estipulação e execução municipal dos programas, dado os altos custos administrativos de um programa implementado em mais de 5.500 municípios. Os progressos da unificação foram consolidados pela Lei Orgânica de Assistência Social (LOAS), que atribuiu a execução de todos os programas de enfrentamento da pobreza ao âmbito municipal. Além disso, um Ministério foi criado em 2004, o Ministério do Desenvolvimento Social e da luta contra a fome (MDS) para unificar, administrar e executar os programas nacionais de desenvolvimento e da Assistência Social.

No âmbito da unificação de programas para o enfrentamento da pobreza, Fenwick (2009) menciona a centralidade dos avanços políticos e conquistas de movimentos sociais, no domínio da proteção social após a Constituição Federal de 1988, que municipalizaram a assistência social e a participação da população na formulação e implementação de tais políticas. A Constituição esteve no centro do debate político daquela época, com temas como democracia e cidadania, com ênfase para as questões relativas à pobreza e aos direitos sociais, mesmo que os discursos não tenham necessariamente gerado práticas eficientes. Isso posto, a pobreza não foi eliminada e nem todos os brasileiros/as gozam de todos os seus direitos, apesar do respaldo constitucional.

'Segundo Lautier (2006), o PBF é um exemplo de política de transferência de renda de grande abrangência, com um alto número de beneficiários e ampla mobilização do aparato governamental, como outras financiadas por instituições internacionais ${ }^{14}$. No que diz respeito a sua abrangência, desde o seu lançamento, o número de famílias beneficiárias passou de 3,6 milhões, em 2003, a 12,4 milhões, em 2009, o que representa, em média, 46 milhões de pessoas, número inédito em termos de políticas sociais no país. Todavia, o impacto do PBF no PIB brasileiro continua mínimo, representando cerca de $0,41 \%{ }^{15}$, um número pequeno frente à magnitude do problema da pobreza no país.

Além disso, o PBF está inserido em um contexto comum aos programas de transferência de renda: a garantia de legitimidade aos seus governos, pois a sua implementação significaria que os governos seriam responsáveis por "fazer qualquer coisa para ajudar os pobres". Dessa forma, seriam apresentados como instrumentos da coesão social, da formação de um corpo coletivo que reincorporaria indivíduos outrora excluídos do seio da cidadania brasileira (Lautier, 2010).

\section{O objetivo do Programa Bolsa Família: a « luta contra a pobreza » e a regulação da miséria}

As discussões sobre as transferências de renda devem ser acompanhadas de uma delimitação metodológica que situe a concepção de pobreza envolvida, tendo em vista sua importância para a implementação do Programa. Nos últimos anos, suas definições somaram conceitos à carência de renda, como a desigualdade, exclusão social e vulnerabilidade. A pobreza seria uma situação na qual as necessidades de sobrevivência não seriam atendidas,

\footnotetext{
${ }^{9}$ Implementado em 2001 pelo governo de Fernando Henrique Cardoso, com a premissa de R\$15,00 por filho matriculado na escola, com frequência mínima de $75 \%$ Além disso, as famílias deveriam possuir renda per inferior a 90,00 reais .

${ }^{10}$ Criado em 2001, consistia na complementação da renda familiar (de R $\$ 15,00$ até $\mathrm{R} \$ 45,00$ por mês) para melhoria da alimentação e das condições de saúde e nutrição, para gestantes; mães que estejam amamentando sus filhos com até 6 meses de idade e crianças de 6 meses a 6 anos de idade.

"Programa de distribuição de renda implementado pelo governo federal brasileiro em 2001, administrado pelo Ministério de Minas e Energia, que consistia no pagamento de R \$15,00 para cada família com renda de até meio salário-mínimo a cada dois meses, como forma de subsidiar a compra de botijões de gás.

${ }^{12}$ Criado a partir dos anos 90, com o objetivo de retirar as crianças entre 5 a 15 anos de situações de trabalho e mantê-las estudando, o programa foi responsável por uma redução no trabalho infantil de $3,6 \%$ a $0,9 \%$ entre as crianças de idades de 5 a 9 anos e de $13,6 \%$ à $5,8 \%$ para as crianças entre 5 a 15 anos. $O$ governo brasileiro estima que o objetivo de erradicação do trabalho infantil deve ser atingido até o ano de 2016. A Convenção n 182 da OIT, de 1999, ratificada pelo Brasil em 2001, demonstra o compromisso do país até essa data. Fonte: http://www.autresbresils.net/IMG/pdf/bolsa.pdf

${ }^{13}$ Avaliação esta que pode ser observada no consenso entre os dois candidatos nas eleições de 2010, tanto o canditado de oposição, José Serra do PSDB quanto a candidata do PT, Dilma Rousseff afirmaram que manteriam e expandiriam o programa.

${ }^{14}$ Devemos assinalar que o programa é financiado, em certa medida, pelo Banco Mundial, que financia programas similares no México e em outros países em desenvolvimento. No ano de 2009, o Banco Mundial previu um investimento de 2, 4 bilhões de dólares no lançamento de programas de transferência direta de renda em outros seis países: Bangladesh, Colombia, Kenya, Macedonia, Pakistão e Filipinas.

${ }^{15}$ Segundo Bruno Lautier, se as alocações não possuem um alto custo para o orçamento, elas pesam bastante no debate político. Em: «La diversité des systèmes de
} protection sociale en Amérique Latine : une proposition de méthode d'analyse des configurations de droits sociaux ». 
não se reduzindo somente à fome, mas ao padrão de vida e a forma como estas diferentes carências podem ser satisfeitas num contexto socioeconômico. Para a Comissão Econômica para América Latina e o Caribe (CEPAL), o fenômeno seria multidimensional, associado ao subconsumo, desnutrição, condições precárias de vida, baixa escolaridade, inserção instável no mercado de trabalho e pouca participação política e social (Melo, 2005).

É nesse sentido que, dentre outros objetivos ${ }^{16}$, a "luta contra a pobreza" é a finalidade mais publicizada do Programa. Segundo o documento do Banco Mundial "The Nuts and Bolts of Brazil's Bolsa Família Program: Implementing Conditional Cash Transfers in a Decentralized Context" (LINDERT; LINDER; HOBBS; BRIÈRE, 2007), sua meta principal seria a quebra da transmissão intergeracional da pobreza através de incentivos para investimentos em capital humano e o empoderamento de famílias beneficiárias ao conectá-las a serviços complementares.

Dessa maneira, o arcabouço teórico de programas como o PBF teria como base uma compreensão multidimensional e intergeracional da pobreza. Nesse caso, a fala de gestores como Chris $\mathrm{Spohr}^{17}$, economista do Banco Asiático de Desenvolvimento, que afirma que as condicionalidades educativas permitem que se rompa o ciclo da pobreza que passa de uma geração a outra e contribui para o fim do trabalho infantil, é ilustrativa de tais prerrogativas. Amartya $\mathrm{Sen}^{18}$ aproxima-se dessa visão ao teorizar sobre a desigualdade de oportunidades para além de um desequilíbrio de recursos e resultados. O teórico atribui ao desenvolvimento humano individual a redução das desigualdades, através do reforço das capacidades das pessoas. Sua concepção de "desenvolvimento como liberdade" (2000), prega uma expansão das liberdades humanas, que reduziria a pobreza. Ao Estado só caberia aumentar essas liberdades, principalmente dos que se encontram em situação de pobreza (Freitas, 2008).

É dessa forma que observamos que a combinação de transferência de renda com acesso aos serviços de base, presente nos programas da maioria dos países em desenvolvimento, reflete uma compreensão na qual a pobreza inscreveria seus déficits em várias dimensões. A ênfase no desenvolvimento humano, particularmente através da escolarização das crianças, é um indicativo de uma preocupação com a continuidade da pobreza. É nesse ponto que enxergamos uma gestão dos riscos sociais como uma dimensão adicional, já que a base teórica do entendimento das formas de "luta contra a pobreza" contaria com elementos que não visariam simplesmente ao aumento da renda no curto prazo, mas também no longo prazo, de forma a romper o ciclo da pobreza intergeracional ${ }^{19}$ (Barrientos e Santibanez, 2009).

É, portanto, anunciada a crítica da regulação da pobreza, formulada principalmente por Lautier e Salama (1995), ao afirmar que programas dessa natureza não rompem o ciclo de produção da pobreza, mas servem como uma forma de regulação da miséria. Segundo os autores, programas de transferência de renda, como o PBF, encontram-se dentro de um campo constituído - o "social" - cuja reprodução não tem como objetivo a eliminação da miséria, mas sua governância, incidindo sobre a capacidade dos pobres em existir e agir livremente dentro de uma relação de poder específica.

Tal relação estaria inserida na ideologia liberal capitalista que arregimentaria os distintos setores sociais em propostas políticas redistributivas, mas conservadoras. Dessa maneira, o social e as "políticas sociais" aparecem como uma estratégia de despolitização das desigualdades, uma forma de tratá-las em termos de gestão, organização e técnicas, ao invés de programas que estabelecessem normativamente um status de cidadania e direitos políticos para seus beneficiários.

O fato de tais políticas terem um propósito regulatório não é novidade, como podemos observar pelos programas implementados na Europa a partir do século XVI. É nesse período que traçamos a gênese dos fundamentos das políticas sociais cujo objetivo era de controle ou pacificação das relações sociais, onde

${ }^{16}$ Junto com o combate a fome e a promoção da segurança alimentar; o incentivo ao acesso aos serviços públicos, principalmente a saúde, educação e a assistência social; a criação de possibilidades de autonomia dos grupos familiares e desenvolvimento local dos territórios.

${ }^{17}$ Fonte: Direct Matin, n 767, 5 Novembro 2010, « Manille à l'assaut de la pauvreté »

${ }^{18}$ Segundo Armand Colin (2009), em : Glossaire "Les mots de Sen..et au-delà «, Revue Tiers Monde, 2009/2 (n 198)

${ }^{19}$ No original em ingles: "aim to break the cycle of intergenerational poverty" (BARRIENTOS e SANTIBANEZ, p.12, 2009). 
a luta contra a pobreza serviria para colocá-la em limites aceitáveis, cumprindo uma função política. Para Lautier (2006), tal funcionalidade dos pobres seria dada por um utilitarismo no qual é seu número que os tornaria politicamente úteis, entendendo que um alto número de pobres seria politicamente perigoso:

O objetivo da eliminação da pobreza, ao entrar na retórica política, sempre escondeu seu objetivo verdadeiro : a regulação da mesma. Se os pobres são politicamente úteis, um excesso de pobres é politicamente perigoso. Tais proposições seguem pertinentes não somente pela luta contra a pobreza contemporânea, como também pela totalidade da proteção social essa também serviria para "pacificar" as relações sociais, a normalizar os comportamentos e a desmobilizar os conflitos (LAUTIER, 2006, p.10) ${ }^{20}$.

É nesse sentido que cabe ressaltar a observação de Lautier (2006) sobre a implementação de programas de transferência de renda como um dever da sociedade a que, paradoxalmente, não corresponderia nenhum direito do cidadão, já que o recebimento do benefício não garantiria o status da cidadania para a população atendida. Ao enquadrá-los na assistência, as transferências são dadas segundo o cumprimento de determinadas condições e regras estritamente definidas. É dessa forma que esse enquadramento não garante a outorga de direitos individuais, mas sim um direito através do pertencimento a uma categoria, que os pobres não podem sequer reivindicar como sua.

Um outro aspecto relativo à falta de referência a direitos do PBF é seu acesso não ser garantido de forma incondicional. A partir do momento em que a quota de famílias atendidas no município é preenchida, a inserção de novas fica "impossibilitada", independentemente de seu grau de vulnerabilidade e, portanto, passíveis do recebimento desse "direito". Freitas (2008) faz uma referência à regulação legal e ao disciplinamento da política, que atuariam em paralelo a uma utilização da mídia para buscar o consenso de seus beneficiários e da sociedade como um todo.

Já Lautier e Salama (1995) encaram a falta de direitos sob a perspectiva de uma certa "infantilização" dos pobres, na medida em que ter seus direitos legitimados não significaria ter a possibilidade de pensar sobre se esses são colocados em prática. A pacificação das relações sociais possui um efeito de normalização dos comportamentos e desmobilização dos conflitos; essa forma de gestão da pobreza seria um dos fatores responsáveis por sua despolitização. Como veremos no item a seguir, o público mais atingido pela pobreza no país, mulheres e negras, apesar do recebimento dos benefícios, ainda sofrem com a falta de acesso ao espaço público e cidadania.

Dessa forma, a questão dos pobres no país passaria a ser encarada como um problema humanitário e não de regulação política. Os pressupostos normativos de ordem moral, elemento das políticas de transferência direta de renda, embasados no emprego de uma determinada linguagem, possuem, a destarte disso, um tratamento técnico, como afirma Lautier (1995, p.6): “uma vez feito o diagnóstico médico, a farmacologia pode intervir. O perigo é a pobreza não absoluta (relativa) acabar sendo naturalizada, se não desculpada. Seu tratamento é, de qualquer forma, postergado ${ }^{21}$.

A cidadania reaparece na crítica da regulação formulada por Lautier (2006), com a falta de rearticulação dos direitos sociais fundados sob o seu o preceito, em oposição aos direitos sociais anteriores, cujo ponto de inflexão tinha como centralidade o status de trabalhadores. O status de cidadão ligado ao trabalho é de difícil vislumbre em um Brasil com um mercado de trabalho cada vez mais precarizado, com a diminuição do número de carteiras assinadas e o aumento dos empregos informais. Para Castel (1998), o trabalho implicaria não somente em técnicas de produção, mas em relações sociais, culturais e identitárias de indivíduos. Para o autor, o conceito de desfiliação expressaria a não inscrição nas relações sociais hegemônicas, que pode se dar

${ }^{20}$ No original em francês (tradução da autora) : » L'objectif d'élimination de la pauvreté, s'il joue un rôle dans la rhétorique politique, a toujours masqué le véritable objectif : réguler la pauvreté. Les pauvres sont politiquement utiles ; trop de pauvres est politiquement dangereux. Ces propositions restent pertinentes non seulemen pour la lutte contre la pauvreté contemporaine mais aussi pour la totalité de la protection sociale : celle-ci sert à « pacifier » les rapports sociaux, à normaliser les comportements et à désamorcer les conflits ».

${ }^{21}$ Tradução da autora. No original Lautier (1995, p.6) « de même qu'une fois fait le diagnostic médical, intervient la pharmacopée). Le danger est alors évidemment que la pauvreté non absolue (relative) est de ce fait même naturalisée, sinon excusée ; son traitement est en tout cas remis à plus tard ». 
pela negação dos indivíduos ou pela falta de oportunidade de acesso.

Dessa maneira, o debate político é, em certa medida, desarticulado de um projeto universalista, já que, para essa assistência - agora desconectada dos direitos ligados ao trabalho -. o auxílio só existe como contrapartida à submissão à nação. Tal ambiguidade, expressa em um auxílio financeiro não vinculado ao trabalho, pode ser interpretada de duas formas: ora como uma ajuda mínima cedida aos pobres para se ver livre do problema, ora como o reconhecimento e contrapartida ao papel reprodutor do cidadão, partícipe da nação, através da família - vida local coletiva -, e na reprodução e transferência de valores simbólicos.

Contudo, nem todos os autores são unânimes em considerar as contrapartidas dessas políticas como um exemplo de gestão da pobreza. Hall (2006) defende que os programas de transferência de renda são também responsáveis por um desenvolvimento de capital humano, ao oferecer outras inovações e vantagens aos usuários em contraposição aos benefícios sociais tradicionais. A formação do capital humano constaria no aumento da responsabilidade da família, com ênfase na saúde, educação e outros componentes considerados essenciais para a vitória sobre o que seria reconhecido como a "luta contra a pobreza".

No entanto, Freitas (2008) considera que o investimento nesse capital significaria maiores recursos à disposição da produção, logo, às futuras gerações. Sua leitura é da ótica de um individualismo produtivo, que beneficiaria os indivíduos capazes de gerar mais renda. A partir dessa lógica, a solução para a pobreza residiria na melhoria das capacidades produtivas das pessoas que, por definição, são pobres porque teriam pouca capacidade produtiva, as pessoas valeriam o que podem produzir economicamente.

\section{A crítica feminista - o papel das mulheres nessa regulação}

É importante ter em conta o público atingido de forma mais direta por programas de transferência de renda: as mulheres, mães de família. Estas estariam inseridas em um período particular, o fim dos anos 80 , quando se tomou consciência sobre os limites do impacto de programas tradicionais de erradicação da pobreza. Foi a partir desse momento em que houve uma mudança de paradigma para iniciativas que não somente buscassem a melhoria da renda dos pobres através de programas participativos, mas também fornecessem ferramentas para a criação de possibilidades efetivas para aqueles que vivem em situação de pobreza (Cortes, 2008).

Nessa época, assistiu-se a um empobrecimento e uma feminilização geral da população na América Latina. Dada a nova face da população, observou-se o crescente empobrecimento das classes médias, que acrescentaram novos públicos-alvo para os programas tradicionais de transferência de renda que passaram dos pobres estruturais para também as mulheres e, particularmente, às famílias dirigidas por elas.

O termo "feminização da pobreza" foi primeiramente utilizado por Diane Pearce (1978) no contexto das mudanças de padrões de gênero nas linhas de pobreza nos Estados Unidos entre as décadas de 50 e $70 . \mathrm{O}$ aumento do número de famílias pobres chefiadas por mulheres passou a ser parte da retórica governamental e das agências de fomento nos EUA a partir da década de 70, associado à ampliação da visibilidade de mulheres entre as mais pobres pelo aumento do divórcio, separações e viuvez.

Segundo Castro (2001), foram as feministas as responsáveis por chamar a atenção para o aumento da visibilidade da pobreza das mulheres, já que, historicamente, o trabalho feminino não remunerado de cuidado não contava como produção de riqueza. Além disso, caso considerada somente a renda individual, seriam as esposas, e não as mulheres chefes de família, as que mais se destacariam como as mais pobres entre os pobres, assim como as mais velhas vivendo sós.

Dada a percepção do crescimento das famílias pobres chefiadas por mulheres, que se acredita proporcionar um maior risco de transmissão intergeracional de pobreza do que as familias nucleares pobres, começou-se a pesquisar, em um escopo maior, o consumo familiar, as condições de saúde e a inserção dos filhos na escola e no mercado de trabalho. Segundo Freitas (2008), é por esse motivo que os programas de transferencia direta de ren- 
da têm como beneficiárias diretas as mulheres cujos filhos menores residem no mesmo domicílio, havendo uma preferência por aquelas que sejam chefes de família.

\subsection{O PBF e as mulheres brasileiras}

Se considerarmos o contexto brasileiro, o PBF se insere em um país onde $33 \%{ }^{22}$ das famílias são chefiadas por mulheres e, segundo o IBASE - Instituto Brasileiro de Análises Sociais e Econômicas ${ }^{23}, 27 \%$ são mães solteiras e $64 \%$ são negras ou pardas. Ao observarmos as características da pobreza no país, assim como a composição dos beneficiários do Programa, entendemos que as mulheres negras constam frequentemente entre as mais pobres, retrato da persistência de uma desigualdade histórica ${ }^{24}$.

Tais desigualdades, marcadas estruturalmente pelo sexo e pela raça, refletem também um processo que afeta a relação entre as mulheres e o Estado, que seria permeada por obrigações impostas pelo aparelho estatal, que estende seus efeitos no tempo e no trabalho das mulheres, sobretudo, a partir das condicionalidades das políticas de transferências de renda. Segundo Mariano e Carloto (2009), tais encargos ampliam outras responsabilidades impostas pela esfera governamental, como a execução de tarefas ligadas ao cuidado das crianças, adolescentes, idosos e doentes. Através de políticas de transferência de renda, as responsáveis pela casa são frequentemente convocadas a participar de atividades suplementares (como, por exemplo, grupos educativos), sendo ainda mais sobrecarregadas de obrigações ligadas à reprodução social.

A crítica feminista começa a incidir a partir desse momento, enfatizando que as mulheres são o público prioritário nesse tipo de política e o principal objeto de intervenção na "luta contra a pobreza". Tendo em vista que a titularidade do Programa é preferencial, e não compulsória às mulheres, ação valorizada por $87,5 \%$ dos beneficiários, segundo o estudo do IBASE, que responderam que as mulheres deveriam ser mesmo as responsáveis pelo re- cebimento do benefício. Podemos inferir, a partir disso, que a prática implementada reforça o imaginário coletivo sobre a exclusividade feminina nas tarefas de reprodução social.

As condicionalidades dos programas de transferência de renda são os principais objetos de crítica de um estudo realizado por Molyneux e Tabbush (2008), em 10 municípios no Brasil, com 145 entrevistas semiestruturadas com beneficiárias do PBF e 54 funcionárias do governo. Tal estudo demonstrou que o benefício fica, via de regra, à cargo das mulheres, sobretudo graças ao caráter das condicionalidades, ligadas à saúde e educação das crianças.

Isso posto, na perspectiva da esfera doméstica e da reprodução, tais mulheres não cumpririam somente o papel de beneficiárias dos programas, mas acumulariam a tarefa de serem as principais interlocutoras de tais ações, responsáveis pelo cumprimento das condicionalidades impostas. Como enfatizado por Molyneux (2006) essa seria a visão tradicional dos papéis de gênero, que residiria na base desse tipo de programa, responsável por reforçar tais relações assimétricas.

A autora, em 2008, afirma que tal reforço não é uma prerrogativa contemporânea, pois, se nos países em desenvolvimento a transferência de dinheiro para as mães visando às crianças é recente, desde a década de 30 , a Europa Ocidental já possuía campanhas que enfatizavam as responsabilidades ditas femininas. As justificativas utilizadas eram semelhantes às atuais, já que reforçariam um papel natural realizado pelas mulheres, que seriam mais responsáveis no que concerne a gestão da unidade familiar e o cuidado com as crianças.

Desde a década de 30, portanto, assistimos a razões consensualizadas pela sociedade para a concentração de recursos financeiros nas mãos das mulheres que teriam como efeito a acentuação de diferenças que justificariam a segmentação de gênero no que tange às responsabilidades domésticas. Todavia, é preciso saber se, ao enfatizar a ligação entre as necessidades das crianças e um modelo maternal ligado aos cuidados e as responsabilidades domésticas, tais programas podem ser

${ }^{22}$ Segundo Luana Pinheiro et al en "Retrato das desigualdades de gênero e raça" 3. ed. Brasília: Ipea; SPM: UNIFEM, 2008.

${ }^{23} \mathrm{Em}$ uma pesquisa em 229 municípios, a partir de $94 \%$ das benefíciarias mulheres do programa. IBASE - 2008 .

${ }^{24}$ Constatado de forma pioneira por Melo (2005), a partir dos dados da Pesquisa Nacional de Amostra de Domicílios (PNAD) do Instituto Brasileiro de Geografia e Estatística (IBGE) em 2001. Seu trabalho mostrou que existiriam fatores de gênero que incidiriam com maior peso na vida das mulheres e que as tornam mais vulneráveis com a relação à pobreza, agravadas pela questão racial. 
responsáveis por reproduzir esse modelo, em particular pelas mães beneficiárias no médio e longo prazo.

Ainda nessa crítica ao reforço dos papéis maternos, Molyneux (2008) busca enfatizar que as políticas contra a pobreza seriam mais eficazes se, ao visarem a um grupo em particular, não aumentassem as desvantagens de um outro grupo vulnerável no mesmo processo - no caso, as mulheres. A prerrogativa que concerne aos programas de transferência de renda seria a produtora de um ciclo vicioso as crianças, as unidades familiares e as mulheres se beneficiariam todos de um dispositivo simples de transferência de dinheiro entregue às mulheres.

O benefício recebido é, sim, empregado quase que totalmente nos gastos familiares, como constatado pelo IBASE (2007), em que as famílias gastariam, em média, R\$ 200,00 mensais com alimentação, cerca de $56 \%$ da renda familiar total. $\mathrm{O}$ dinheiro recebido com o PBF seria empregado principalmente com determinados itens para o bem-estar doméstico, em ordem: alimentação (87\%), material escolar (46\%), vestuário (37\%) e remédios (22\%). Dessa forma, podemos perceber que as necessidades da família são atendidas, mas não existe uma medida de valorização da mulher de forma autônoma nesse processo.

No que tange às múltiplas relações dos que vivem em situação de pobreza, programas como o Bolsa Família costumam reproduzir as prerrogativas que tratam a pobreza como uma necessidade social descontextualizada, retirando elementos essenciais na reprodução social, entre os quais as relações de gênero. As diretrizes governamentais de programas como o $\mathrm{PBF}$ alegam, entretanto, ir além dessas concepções graças à participação e empoderamento femininos, decorrente do aumento da renda. A prática, apesar disso, vê programas fundados sobre concepções de papéis sociais das mulheres que não levam em consideração suas necessidades diferenciadas ou os riscos sociais a que são confrontadas (Molyneux, 2007).

As próprias diretrizes do Banco Mundial reforçam os estereótipos de gênero, ao afirmar que as mulheres seriam as mais in- dicadas a receber o benefício, pois refletiriam "a evidência internacional e brasileira que as mulheres são mais propensas a investir a renda adicional no bem-estar de seus filhos" (World Bank, 2007, p. 52).

Tendo em vista que é um dos principais financiadores do Programa, o Banco Mundial ${ }^{25}$ afirma que a forma como o pagamento é executado, via cartão bancário, se apresentaria como uma das vantagens da política. A utilização dos bancos reduziria as possibilidades de clientelismos - uma vez que as autoridades públicas não estariam envolvidas na entrega de prestações diretamente aos beneficiários - e criaria um vínculo inédito entre as beneficiárias do PBF - pobres - ao sistema bancário, auxiliando em seu desenvolvimento e na promoção de sua identidade e autoestima. Todavia, o processo inaugura uma nova forma de subalternização das mulheres, na medida em que ficam submetidas a um modelo de clientelismo local, como vigilantes das condicionalidades.

É interessante notar a desvantagem sublinhada pelo $\mathrm{BM}$ a respeito dessa forma de distribuição, que seria a perda de pontos de contatos com as beneficiárias do Programa e os funcionários, outrora úteis para o monitoramento das condicionalidades e para a verificação de dados de base. Dessa forma, os financiadores deixam implícito seu caráter regulatório, uma relação de outorga de um benefício frente ao cumprimento de determinadas condições.

O cumprimento das condições estabelecidas a partir do já explicitado contexto frequente de famílias monoparentais, onde as mulheres são as responsáveis únicas pelo sustento de suas casas, conta com contextos de privações adicionais. A ausência de serviços públicos de saúde e educação eficazes faz com que as beneficiárias, segundo elas proprias, se tornem as únicas responsáveis por todo o processo. O simples aumento na renda não é capaz de superar a situação precária da saúde e da educação de alguns municípios do Brasil, em que somente $42,6 \%$ das famílias têm acesso à rede de esgotos ${ }^{26} \mathrm{e} 70,3 \%$ utilizam o gás de botijão como principal energia para cozinhar.

A situação é tal que, em determinados locais do país, famílias inteiras não conseguem

${ }^{25}$ Segundo o documento "Nuts and Bolts of Bolsa Família", de 1997.

${ }^{26}$ Segundo o estudo do IBASE "Repercussões do Programa Bolsa Família na segurança alimentar e nutricional das famílias beneficiadas", de 2008.

${ }^{27}$ Segundo dados do Censo Escolar do MEC de 2009. 
aceder ao PBF, pois seus filhos não possuem qualquer registro civil. Além disso, a falta de creches é um problema para as mães em mais de 827 municípios $^{27}$, que não podem contar com um lugar para seus filhos entre 0 e 3 anos.

Alheios à situação de pobreza estrutural em muitas partes do país, para o Banco Mundial $^{28}$, o não cumprimento das condicionalidades representa um sinal para os gestores de que as famílias beneficiadas possam estar em risco ou precisando de serviços adicionais. Os responsáveis pelo PBF já afirmaram repetidamente que o foco do programa é auxiliar as famílias a cumprirem as condicionalidades e não puni-las em caso de não cumprimento. Todavia, o não cumprimento sucessivo invocaria o aspecto "contratual" do Programa, levando ao bloqueio do benefício, suspensão e ao posterior cancelamento.

\subsection{A crítica ao empoderamento femi- nino providenciado pelo $\mathrm{PBF}$}

O empoderamento ${ }^{29}$ das mulheres, proporcionado pelo Programa, um dos subtemas do PBF, assim como o aspecto de gênero, apesar de não constarem oficialmente em suas normativas e diretrizes segundo o IBASE (2007), são objetivos implícitos da política, enfatizados por seus gestores e financiadores. Se, por um lado, os recursos financeiros são uma fonte de renda e, portanto, uma forma de empoderar as mulheres, por outro, existem limitações dadas às próprias relações entre homens e mulheres, como demonstrado por Todorova (2009). Segundo a autora, para que o aumento da renda pudesse transformar as relações de gênero dentro das famílias, seria necessária uma participação dos cônjuges nas condicionalidades, fato pouco usual. $\mathrm{Na}$ Argentina, por exemplo, os homens dizem que o seu cumprimento ${ }^{30}$ cabe às mulheres e, portanto, eles teriam vergonha de participar.

A utilização da retórica do empoderamento não é novidade, fazendo parte das políticas públicas voltadas para as mulheres desde a década de 1970, vinculadas ao movimento feminista e a organizações da sociedade civil, de forma a aumentar a autoconfiança feminina. Segundo Freitas (2008), contanto, para que tais políticas conduzam a um real empoderamento de mulheres em situação de pobreza, seria necessário mais do que as discussões e treinamentos existentes nos programas como o PBF. A autora sublinha que, apesar de poder funcionar como o pontapé inicial do processo, não haveria a possibilidade de solidificá-lo, já que as mulheres efetivamente não participam dos processos decisórios relativos à concepção, execução e à avaliação dos Programas.

Para Caldeira (2007), ao ligar o cumprimento das condicionalidades ao bem-estar de crianças, adolescentes e mães, sem intervir diretamente no dos demais integrantes das família, se reitera a permanência de uma relação assimétrica de poder e a manutenção de uma relação de interdependência. Situação oposta ao que se espera da realidade do empoderamento, que deveria diminuir o isolamento social feminino e aumentar sua visibilidade, principalmente na esfera pública, algo não observado no estado atual do PBF. Há também um excesso de responsabilidades delegadas às famílias por um Estado incapaz de controlar socialmente os impactos provocados por mudanças relativas ao trabalho, à educação e à saúde.

A possibilidade de empoderamento real de programas como o PBF é também relativizada por Molyneux (2008), ao afirmar que seria possível aumentar a autonomia e sociabilidade de algumas mulheres em suas famílias, todavia com alguns "efeitos colaterais". Estes efeitos podem ser percebidos em alguns contextos em que o ingresso no PBF provocou a criação ou mesmo o acirramento de certas tensões entre os casais, levando-os a situações de violência, na medida em que os maridos se recusam a agir em um ambiente de maior autonomia feminina.

De acordo com Molyneux e Tabbush $(2008)^{31}$, há diferentes discursos sobre o empoderamento: a fala dos gestores e das mu-

\footnotetext{
${ }^{28}$ Segundo o documento "Nuts and Bolts", de 2007.

${ }^{29}$ Empoderamento é um termo comumento utilizado por ONGs, tradução do inglês empowerement, que diria respeito a uma alteração radical dos processos e das estruturas que reproduziriam a posição da mulher como submissa. O termo chama a atenção para a palavra "poder" e sua relação social, que implicaria em uma fonte de opressão, autoritarismo, abuso e dominação. O feminismo, porém, fala deste como uma fonte de emancipação e forma de resistência (LISBOA, 2008).

${ }^{30}$ O Programa "Plan Jefes y Jefas de Hogar Desocupados", implementado no país em 2001, objetiva a transferência de renda para famílias com adultos desempregados que tenham dependentes até a idade de 18 anos ou com pessoas com qualquer tipo de deficiência (física ou mental). Fonte: Armando Barrientos, Miguel Niño-Zarazúa and Mathilde Maitrot. Social Assistance in Developing Countries Database - Brooks World Poverty Institute (2010)

${ }^{31} \mathrm{Os}$ resultados dessa pesquisa dizem respeito à avaliação do Programa Oportunidades, no México.
} 
lheres, responsáveis pela renda, que se intercruzam. Os primeiros afirmam aumentar a capacitação das mulheres e seus rendimentos através da aprendizagem na educação, saúde e, principalmente, com a criação de uma rede de solidariedade, que as tornaria mais confiantes em si mesmas. É nesse sentido que os discursos de $48,8 \%$ das mulheres ${ }^{32}$ confirmam essa avaliação, pois afirmaram se sentirem mais independentes financeiramente e $39,2 \%$ afirmaram que seu poder de decisão em relação ao destino do dinheiro da família aumentou.

Segundo o IBASE (2008), o empoderamento providenciado pelo Programa seria o resultado do desenvolvimento de um capital social e da aprendizagem através da participação em grupo. Todavia, Molyneux e Tabbush (2008) verificaram que não houve mudanças no que tange à tomada de decisões, que continuaria restrita às interações sociais femininas mais imediatas, apesar do aumento do poder de decisão em relação às despesas de casa, domínio previamente exclusivo dos homens.

As críticas feministas sobre o cumprimento das condicionalidades se intercruzam com o advogado empoderamento do PBF, na medida em que há uma sobrecarga de tarefas nos domínios da educação, saúde ou assistência à criança. Tais tarefas, culturalmente relegadas às mulheres, não podem ser empoderadoras, na medida em que consomem tempo e energia que poderia ser utilizada para a obtenção de condições de igualdade nos processos políticos e de espaços no mercado de trabalho, contribuindo para a manutenção das desigualdades entre os gêneros (MEDEIROS, BRITTO \& SOARES, 2007). Em última instância, o preenchimento das tarefas impediria a maior participação das mulheres nos espaços públicos.

A respeito da inclusão alegadamente proporcionada pelo PBF, se por um lado a política tem como um de seus objetivos incluir as mulheres outrora desconsideradas no seio da cidadania brasileira, principalmente através da utilização de documentos de identidade (e do registro bancári o dos beneficiárias/os), nem sempre o efeito gerado é uma inclusão cidadã. Segundo Molyneux e Tabbush (2008), é recorrente um desconhecimento das mulheres sobre a regulamentação e objetivos do Programa, que saberiam somente que devem receber uma quantia mensal fixa.
No que tange à alegação do aumento da visibilidade social das beneficiárias, através da elevação do seu poder de consumo e de compra, é preciso dimensionar a inclusão social proporcionada pelo PBF. Se em muitos casos o aumento da renda é capaz de retirar famílias de situações de miserabilidade, ainda assim é preciso ter em conta que restam casos em que a renda providenciada não seria suficiente para trazer tamanho impacto no orçamento doméstico. Dessa forma, estando limitada à esfera da sobrevivência, os benefícios não teriam a capacidade de proporcionar uma maior noção de direitos e cidadania (Molyneux e Constanza, 2008).

\section{Conclusão}

À guisa de conclusão, é importante situar quem são, em sua maioria, as beneficiárias do Programa Bolsa Família no Brasil, mulheres chefes de família, negras e pobres. Berquó (2002), afirma que o número de domicílios chefiados por mulheres era de $26 \%$ em 1999, sendo que as mulheres negras sem cônjuge, mas com filhos, em 1998, representavam $20,7 \%$ da população . É nesse contexto que se inserem as transferências diretas de renda, características do Estado brasileiro a partir dos anos 2000, frequentemente uma responsabilidade das mulheres, sobretudo por suas condicionalidades ligadas à saúde e à educação infantil.

Tais responsabilidades geram, com frequência, uma sobrecarga de trabalho imposta às mulheres. Além disso, os princípios de igualdade dentro da concepção do Programa, que teriam o empoderamento feminino como um de seus subtemas, não parecem possuir o efeito esperado quando se observa que é pouco usual que as relações de poder entre os casais sejam modificadas.

É nesse sentido que a crítica feminista chama a atenção para o fato de que é necessário uma corresponsabilidade, ou seja, um maior envolvimento dos homens nesse tipo de programa. Além disso, para que o alegado empoderamento das mulheres fosse real, seria necessário, segundo Molyneux (2008), que os recursos fossem empregados de forma a melhorar as capacidades das mulheres em assegurar sua independência econômica e seu bem-estar 
físico e mental. A autora afirma que o aumento da autonomia social e econômica das mulheres deve constar como um dos objetivos do PBF, com instrumentos para mensuração.

Freitas (2008) afirma que o objetivo do PBF de superação da pobreza não deve ter como prerrogativa a ideia de rede de proteção social como emergência de curto prazo, pois não seriam políticas que atuam no nível dos princípios que determinam as tensões próprias da questão social. O Programa deveria, para a autora, integrar as partes, pobres e ricas, empregadas e desempregadas, de um modo radicalmente diferente do atual, de forma a inserir de forma efetiva na discussão de políticas de combate à pobreza, questões ligadas à classe social, raça e gênero.

A questão da inserção profissional das mulheres é levantada por Lavinas e Nicolli (2006), que afirmam que, junto ao nascimento do discurso da feminização da pobreza adotado pelos governos e instituições internacionais, houve um aumento da visibilidade das mulheres pobres nos programas de transferência direta de renda, ligado ao cumprimento das condicionalidades. Todavia, a promessa de vencer a "luta contra a pobreza" não inclui políticas ligadas à inserção dessas mulheres no mercado de trabalho. Tal falha é apontada também por Molyneux (2007), que afirma que os programas que não possuem essa diretriz seriam incapazes de reduzir a vulnerabilidade feminina.

O estudo realizado pelo IBASE (2008) é também categórico em afirmar que apesar de algumas melhorias visíveis na vida das mulheres, como o aumento de sua independência financeira, maior influência no planejamento dos gastos, e um sentimento de respeito ao aumentar sua influência no âmbito familiar e na comunidade, continua baixo o investimento em políticas capazes de garantir a inserção das mulheres no mercado de trabalho.

O caso brasileiro precisa ser considerado - frente às demandas para além de um benefício instituído - como política social da forma que as políticas de transferência de renda o são. As mulheres pobres brasileiras necessitam também de meios para autonomizar-se dentro das relações de gênero e nas posições dentro do mercado de trabalho. Faz-se, então, necessárias políticas complementares como o fornecimento de creches e escolas públicas de tempo integral, que seriam iniciativas em favor da inclusão das mulheres na vida produtiva e, por consequência, na redução da pobreza de suas unidades familiares.

\section{Referências Bibliograficas}

BARRIENTOS, A e SANTIBANEZ, C. New Forms of Social Assistance and the Evolution of Social Protection in Latin America, Journal of Latin American Studies, 41, 2009, pp. 1-26.

BARRIENTOS, A, NINO-ZARAZUA, $M$ e MAITROT, M. Social Assistance in Developing Countries Database - Versao 5.0 -Brooks World Poverty Institute The University of Manchester, 2010.

BERQUO, E.Perfil demográfico das chefias femininas no Brasil. In: Bruschini,Cristina;Un behaum,Sandra G., Org. Gênero, democracia e sociedade brasileira. São Paulo: Fundação Carlos Chagas, Editora 34, 2002.

CASTEL, R. As metamorfoses da questão social: uma crônica do salário. Petrópolis, RJ: Vozes, 1998.

CASTRO,M G. Feminização da pobreza em cenário neoliberal. In: Galeazzi,Irene M. S., org. Mulher e trabalho. Porto Alegre: PEDRMPA, 2001.

CORTES, R. The Contemporary Social Policy Debate in Latin America. Global Social Policy, 2008, pp.8-109.

FENWICK, T B. Avoiding Governors -The Success of Bolsa Família. Latin American Research Review, Volume 44, Number 1, 2009, pp. 102-131

HALL, A. From Fome Zero to Bolsa Família: Social Policies and Poverty Alleviation under Lula J. Lat. Amer. Stud. 38, 2006, pp.689-709.

IBASE - Instituto Brasileiro de Análises Sociais e Econômicas. Repercussões do Programa Bolsa Família na Segurança Alimentar e Nutricional das Famílias benefíciadas - Documento Síntese, 2008. 
KABBER, N. Can the MDGs provide a pathway to social justice? The challenge of intersecting inequalities - Institute of Development Studies, 2010. Disponível em: http://www.ids.ac.uk/go/idspublication/ can-the-mdgs-provide-a-pathway-to-socialjustice-the-challenges-of-intersectinginequalities. Acessado em Janeiro, 2011.

LAUTIER, B. SALAMA, P. De l'histoire de la pauvreté en Europe à la pauvreté dans le Tiers Monde In: Tiers-Monde.V.36 n¹42, 1995, pp. 245-255.

LAUTIER, B. Le difficile cheminement vers l'universalisation de la protection sociale en Amérique latine. Colloque État et régulation sociale CES-Matisse Paris, 11-13 Setembro 2006.

La protection sociale dans le

Brésil de Lula : trop de dépenses, ou trop peu de recettes ? In: Tiers-Monde. V.44, n 175, 2003, pp. 527-554.

Les malheureux sont les puissants de la terre. In: Tiers-Monde. 1995, tome $36 \mathrm{n}^{\circ} 142.1995$, pp. 383-409.

\section{Les Politiques Sociales a}

l'épreuve des reformes de marché. Revue Internationale de Politique Comparée, Vol. $17, \mathrm{n}^{\circ} 3,2010$.

LAVINAS, Lena et NICOLLI, Marcelo. Pobreza, transferências de renda e desigualdades de gênero: conexões diversas. Parcerias estratégicas / Centro de Gestão e Estudos Estratégicos. - Vol. 1, n. 1 (maio 1996). Brasília : Centro de Gestão e Estudos Estratégicos : Ministério da Ciência e Tecnologia, 2006.

LINDERT, K; LINDER, A.; HOBBS, J; BRIÈRE, B. The nuts and bolts of Brazil's Bolsa Família Program: implementing conditional cash transfers in a decentralized context. Washington, DC: World Bank, (Social Protection Discussion Paper, n. 709), 2007.

\section{MARIANO, S A e CARLOTO, C M. Gênero} e combate à pobreza: programa Bolsa Família. Rev. Estud. Fem. [online]. 2009, vol.17, n.3, pp. 901-908.
MELO, H P. Gênero e Pobreza no Brasil. Brasília: CEPAL, 2005, 47p.

MOLYNEUX, M. Conditional Cash Transfers and Women's empowerment: Annotated Bibliography, 2008.

Conditional Cash Transfers:

Pathways to women's Empowerment?, Research Paper, IDS Series on Social Policy in Developing Countries, 2008, pp 1-97.

Change and Continuity in

Social Protection in Latin America - Mothers at the Service of the State? United Nations Research Institute for Social Development - UNRISC - Gender and Development Programme Paper Number 1, 2007.

SUGIYAMA, N B. Ideology and Networks The Politics of Social Policy Diffusion in Brazil - Latin American Research Review, Volume 43, Number 3, 2008, pp. 82-108

TODOROVA, Z. Center for Full Employment and Price Stability Working Paper Series - Employer of Last Resort Policy and Feminist Economics: Social Provisioning and Socialization of Investment Working Paper 56, 2009.

Endereço para Correspondência:

Simone da Silva Ribeiro Gomes

s.ribeirogomes@gmail.com

Rua Pereira da Silva 302 - 1302 - Icaraí

Niterói - Rio de Janeiro

CEP: 24220031 